\title{
BMJ Open Reduced risk of pre-eclampsia with organic vegetable consumption: results from the prospective Norwegian Mother and Child Cohort Study
}

\author{
Hanne Torjusen, ${ }^{1,2}$ Anne Lise Brantsæter, ${ }^{2}$ Margaretha Haugen, ${ }^{2}$ Jan Alexander, ${ }^{3}$ \\ Leiv S Bakketeig, ${ }^{4}$ Geir Lieblein, ${ }^{5}$ Hein Stigum, ${ }^{4}$ Tormod Næs, ${ }^{6,7}$ Jackie Swartz, ${ }^{8,9}$ \\ Gerd Holmboe-Ottesen, ${ }^{10}$ Gun Roos, ${ }^{2}$ Helle Margrete Meltzer ${ }^{2}$
}

To cite: Torjusen $\mathrm{H}$, Brantsæter AL, Haugen M, et al. Reduced risk of preeclampsia with organic vegetable consumption: results from the prospective Norwegian Mother and Child Cohort Study. BMJ Open 2014;4:e006143.

doi:10.1136/bmjopen-2014006143

- Prepublication history for this paper is available online. To view these files please visit the journal online (http://dx.doi.org/10.1136/ bmjopen-2014-006143).

Received 17 July 2014 Accepted 28 July 2014

CrossMark

For numbered affiliations see end of article.

Correspondence to

Hanne Torjusen;

hanne.torjusen@sifo.no

\section{ABSTRACT}

Objective: Little is known about the potential health effects of eating organic food either in the general population or during pregnancy. The aim of this study was to examine associations between organic food consumption during pregnancy and the risk of preeclampsia among nulliparous Norwegian women.

Design: Prospective cohort study.

Setting: Norway, years 2002-2008.

Participants: 28192 pregnant women (nulliparous, answered food frequency questionnaire and general health questionnaire in mid-pregnancy and no missing information on height, body weight or gestational weight gain).

Main outcome measure: Relative risk was estimated as ORs by performing binary logistic regression with pre-eclampsia as the outcome and organic food consumption as the exposure.

Results: The prevalence of pre-eclampsia in the study sample was $5.3 \%(n=1491)$. Women who reported to have eaten organic vegetables 'often' or 'mostly' $(\mathrm{n}=2493,8.8 \%)$ had lower risk of pre-eclampsia than those who reported 'never/rarely' or 'sometimes' (crude $\mathrm{OR}=0.76,95 \% \mathrm{Cl} 0.61$ to 0.96 ; adjusted $\mathrm{OR}=0.79,95 \%$ $\mathrm{Cl} 0.62$ to 0.99 ). The lower risk associated with high organic vegetable consumption was evident also when adjusting for overall dietary quality, assessed as scores on a healthy food pattern derived by principal component analysis. No associations with pre-eclampsia were found for high intake of organic fruit, cereals, eggs or milk, or a combined index reflecting organic consumption.

Conclusions: These results show that choosing organically grown vegetables during pregnancy was associated with reduced risk of pre-eclampsia. Possible explanations for an association between pre-eclampsia and use of organic vegetables could be that organic vegetables may change the exposure to pesticides, secondary plant metabolites and/or influence the composition of the gut microbiota.

\section{INTRODUCTION}

Pre-eclampsia is one of the major causes of maternal and perinatal morbidity and

\section{Strengths and limitations of this study}

- This is the first study to report an association between use of organically grown vegetables during pregnancy and reduced risk of preeclampsia. Consumption of plant food, including vegetables, is recommended to all pregnant women, and this study shows that choosing organically grown vegetables may yield additional benefits.

- The lower risk of pre-eclampsia among women who consumed organic vegetables was observed independently of a healthy food pattern including a generally higher vegetable intake.

- Major strengths of this study include the prospective design; the large sample of women from all regions of Norway, including all age and socioeconomic groups; and detailed information on diet and potential confounding factors.

- Since this study is observational, no causal implications can be drawn, and although confounding by other variables was carefully considered, residual confounding cannot be excluded.

mortality worldwide, affecting $2-8 \%$ of pregnancies. ${ }^{1}{ }^{2}$ The aetiology of pre-eclampsia is largely unknown, but increasing evidence suggests an excessive maternal systematic inflammatory response to pregnancy. ${ }^{3-7}$ Pre-eclamptic pregnancies are characterised by endothelial dysfunction, disturbed placentation, oxidative stress and an exaggerated inflammatory response to pregnancy. ${ }^{8}$ Known risk factors include first pregnancy, obesity and other cardiovascular risk factors. ${ }^{29}$

The maternal diet is one of many factors suggested to play a role in the aetiology of pre-eclampsia. ${ }^{10} 11$ In a previous study in the Norwegian Mother and Child Cohort Study (MoBa), we found that high scores on a healthy diet characterised by high intake of vegetables, fruits and vegetable oils was 
associated with reduced risk of pre-eclampsia in nulliparous women. ${ }^{12}$ Dietary components and qualities associated with pre-eclampsia risk in observational studies include macronutrients, micronutrients, dietary fibre, and individual foods as well as overall food patterns. ${ }^{10-16}$ Trials aiming at pre-eclampsia prevention have yielded mixed results. Some evidence has been indicated for calcium supplementation, ${ }^{17}{ }^{18}$ while a review of 15 studies concluded that available evidence does not support the use of antioxidants, e.g. vitamin $\mathrm{C}$ and $\mathrm{E}$, for the prevention of pre-eclampsia. ${ }^{19}$

Organic agriculture is a production system that relies on ecological processes, biodiversity and cycles adapted to local conditions, aiming at sustaining the health of soils, ecosystems and people. ${ }^{20}$ Organically produced food is produced without the application of synthetic pesticides, synthetic fertilisers or genetically modified organisms. All food sold as organic in Norway must, in agreement with the Norwegian Food Safety Authorities, be certified by Debio and labelled with Debio's $\varnothing$-label, which ensures that regulations for organic production are met, following the EU Council Regulation 2092/91. ${ }^{21}$

Several reviews have concluded that organic foods have been convincingly demonstrated to expose consumers to fewer and lower levels of pesticide residues. ${ }^{22-25}$ Lower urinary excretion of pesticide metabolites have been found in children eating a predominantly organic diet compared with children eating conventional diets. ${ }^{26}{ }^{27}$ Little difference is reported for most nutrients, except a higher content of phosphorus in organic foods, ${ }^{22}$ while higher levels of secondary plant metabolites as well as differences in the microflora on organically compared with conventionally grown plant food have been described. ${ }^{28}{ }^{29}$ Sales of organic food has increased in recent years, ${ }^{30}$ and one of the main reasons for consumers to choose organic food is that they perceive it as healthier, as well as better for the environment and animal health. ${ }^{31}$

Little is known about potential health effects of eating organic food either in general or during pregnancy. In the Norwegian Mother and Child Cohort Study, the dietary questionnaire administered in mid-pregnancy included a question about consumption of organic food in six food groups (vegetables, fruits, cereals, milk/dairy, eggs and meat). We have previously reported that frequent consumption of organic food during pregnancy was not solely associated with socioeconomic and lifestyle factors that are normally associated with good health. ${ }^{32}$ However, the women who chose organically produced food had a healthier dietary pattern with more vegetables, fruit and berries, cooking oil, whole grain and cereal products, and less meat, including processed meat, white bread, and cakes and sweets than women with no or low organic consumption. ${ }^{33}$

The aim of the present study was to investigate whether consumption of organic food during pregnancy was associated with the risk of pre-eclampsia, taking the overall food pattern into account.

\section{METHODS}

\section{Population and study design}

The data set is part of the Norwegian Mother and Child Cohort Study, which is initiated by and maintained by the Norwegian Institute of Public Health. ${ }^{34}$ Participants were recruited from all over Norway in the years 1999-2008. The women consented to participation in $40.6 \%$ of the pregnancies. The cohort now includes 114500 children, 95200 mothers and 75200 fathers. Pregnant women were recruited to the study by postal invitation after they had signed up for the routine ultrasound examination in their local hospital. ${ }^{34}$ The women were asked to provide biological samples and to answer questionnaires covering a wide range of information. The cohort database is linked to the Medical Birth Registry of Norway. ${ }^{35}$ The Norwegian Mother and Child Cohort study has been approved by the Regional Committee for Ethics in Medical Research and the Data Inspectorate in Norway.

This study uses V.4 of the data files made available for research in January 2009. To be included in the present study, the women had to have responded to the baseline questionnaire in the Norwegian Mother and Child Cohort Study as well as the food frequency questionnaire in gestational weeks 17-22. In addition, participants had to have answered at least one of the 6 questions about organic food, and they had to have reported a credible daily energy intake $(>4.5$ or $<20 \mathrm{MJ})$. In total, 63808 pregnancies fulfilled these criteria and this population has been described in detail previously. ${ }^{33}$ From the eligible population of $n=63808$, we excluded pregnancies not registered in the Medical Birth Registry of Norway with a singleton delivery $(\mathrm{n}=1475)$. We further excluded multiparous women $(n=29111)$ due to the special importance of parity for the prevalence and aetiology of pre-eclampsia. We also excluded participants with missing data on height or weight $(n=736)$ and gestational weight gain $(n=4294)$. This resulted in a final sample of 28192 nulliparous women for studying associations between organic food and pre-eclampsia (figure 1). The prevalence of pre-eclampsia was higher in the study population than in the 35616 excluded pregnancies $5.3 \%$ (1491 cases) vs $3.1 \%$ (1068 cases)). Women in the study sample were younger (29 vs 31 years), had higher levels of education ( $27.2 \%$ vs $21.5 \%$ with 17 years or more of educational attainment), fewer who smoked cigarettes in pregnancy $(6.9 \%$ vs $9.6 \%)$ and fewer with high consumption of organic vegetables $(6.9 \%$ vs $7.7 \%)$.

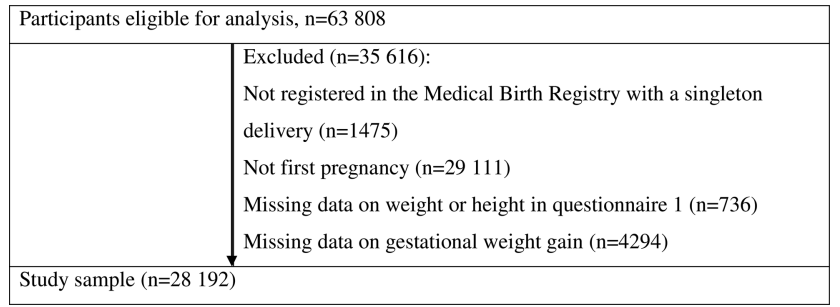

Figure 1 Flow chart showing selection of study participants from the Norwegian Mother and Child Cohort Study. 


\section{Consumption of organic food}

Information about consumption of organic food is based on 6 questions about specified organic food groups included in the food frequency questionnaire of the Norwegian Mother and Child Cohort Study (http:// www.fhi.no/dokumenter/011fbd699d.pdf). This is a semiquantitative food frequency questionnaire designed to capture dietary habits during the first 4-5 months of pregnancy, described in detail elsewhere. ${ }^{36}$ The mean \pm SD gestational age when answering the food frequency questionnaire was $20.7 \pm 3.7$ weeks. The response alternatives for consumption of organic food were: 'never or seldom', 'sometimes', 'often' or 'mostly' and were given values from 0-3. For those who had answered at least one of the questions about organic food, missing values for one or more of the other questions were interpreted as 'seldom or never'. In addition to data on the frequency of consumption of organic food in each of the six food categories, we calculated a 'sum index' variable as a measure of total organic food consumption. The sum index reflects organic food consumption on a scale ranging from 0 to 18 , with 0 representing no use of organic food and 18 representing 'mostly' organic for all six food groups. For respondents who had no reported intake of meat $(n=450)$, eggs $(n=1976)$, milk/dairy $(n=979)$ or vegetables $(n=11)$ and who had not reported organic consumption of the corresponding food group, we upscaled the sum index by multiplying with $6 / 5$ for each omitted food category. For more details about the combined index, see Torjusen et al. ${ }^{33}$ We defined frequent organic consumption as having a sum index of $>6$, which corresponds to having reported eating organic food 'often' for at least one of the six food categories. Consumption of organic food was operationalised in the analyses as 'no or low' vs 'frequent' consumption of organic food (sum index $\leq 6$ vs $>6$ ) and as 'low' ('never/ seldom' or 'sometimes') vs 'high' ('often' or 'mostly)' consumption of the individual six food groups: milk and dairy products, bread and cereal products, egg, vegetables, fruit and meat. The reported frequencies of the six main organic food groups as well as correlations between them have been reported in detail previously. ${ }^{32}$

\section{Pre-eclampsia}

The main outcome was pre-eclampsia as registered in the Medical Birth Registry of Norway. ${ }^{35}$ Information provided to the registry is based on the forms completed by the midwives after birth. The form has 5 check-off boxes relevant to pre-eclampsia: haemolysis, elevated liver enzymes and low platelet count (HELLP syndrome); eclampsia; early pre-eclampsia (diagnosed before 34 weeks); mild pre-eclampsia and severe pre-eclampsia. The diagnostic criteria for pre-eclampsia were given if any of the aforementioned diagnoses were present. Women with chronic hypertension were included in the case group only if they also developed proteinuria. The diagnostic criteria for pre-eclampsia in Norway, according to the guidelines issued by the Society for
Gynecology, are blood pressure $>140 / 90$ after 20 weeks of gestation, combined with proteinuria $>+1$ dipstick on at least 2 occasions. Pre-eclampsia is diagnosed as severe pre-eclampsia if blood pressure is $\geq 160 / 110 .^{37}$ In Norway, all pregnant women receive free antenatal care. Blood pressure measurement and urinalysis for protein are carried out at each antenatal visit.

\section{Covariates}

Hypertension prior to pregnancy (yes/no) was based on diagnoses by a physician reported in the Medical Birth Registry of Norway. Information about parity was retrieved both from the Medical Birth Registry of Norway and from the baseline questionnaire and combined into one variable. Self-reported pre-pregnancy height and weight were used to calculate body mass index $\left(\mathrm{BMI} ; \mathrm{kg} / \mathrm{m}^{2}\right)$. Gestational weight gain was calculated from self-reported pre-pregnancy weight (baseline questionnaire) and self-reported weight at the end of pregnancy (reported in the questionnaire answered 6 months postpartum). Information about educational attainment was retrieved from the baseline questionnaire and divided into four categories (high school or less ( $\leq 12$ years), $3-4$ years of college/university (13-16 years), 4 years or more of college/university (17+years), or other/missing values $(\mathrm{n}=584))$. Maternal age at delivery was retrieved from the Medical Birth Registry of Norway and divided into four categories (14-20, 20-29, $30-40$ and 40-46 years). Smoking in pregnancy was divided into three categories (non-smokers, occasional smokers and daily smokers) based on information from the baseline questionnaire. Household income was expressed as a combination of the participant's and her partner's income, as reported in the baseline questionnaire (both $<300000 \mathrm{NOK}$, one $\geq 300000 \mathrm{NOK}$, both $\geq$ 300000 NOK or missing values $(n=632))$. The food frequency questionnaire provided dietary information in this study. Overall food pattern was described as scores on a principal component denoted as a 'health and sustainability component', derived by principal component analysis and ranked into tertiles. ${ }^{33}$ Dietary supplement use reported in the food frequency questionnaire was computed as a categorical variable with three categories: no supplement use, use of any supplement without vitamin $\mathrm{D}$ and use of a vitamin $\mathrm{D}$ containing supplement.

In the Norwegian Mother and Child Cohort Study, $>99 \%$ of the participants is of Caucasian ethnicity, so ethnicity is not a relevant confounder.

\section{Statistical methods}

Frequencies and descriptive statistics were expressed as $n$ (\%) and as means and SDs. For testing group differences, we used independent samples $\mathrm{t}$ test for continuous variables and $\chi^{2}$ test for categorical variables.

For one analysis (figure 2), organic food consumption was modelled according to the four ordered alternative answer (never/rarely, sometimes, often, mostly) while 


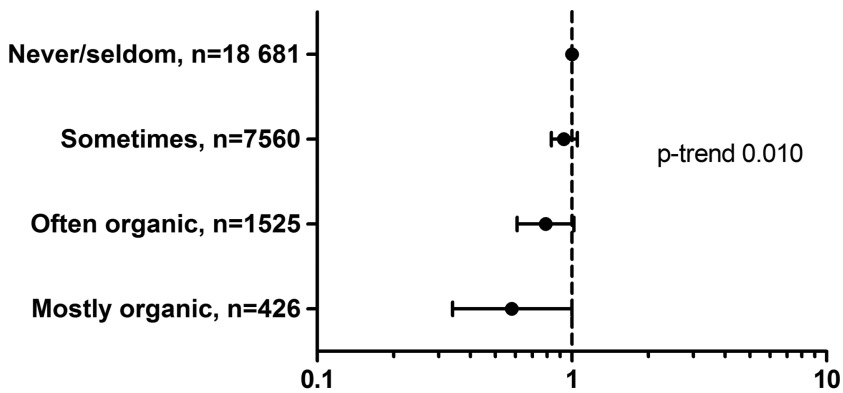

OR $(95 \% \mathrm{Cl})$

Figure 2 Associations (ORs and 95\% Cls) between reported consumption of organic vegetables and pre-eclampsia among 28192 pregnant women in the Norwegian Mother and Child Cohort Study 2002-2008.

for the remaining analyses it was modelled as a dichotomous variable with the two lowest frequencies combined into 'low' and the two highest frequencies combined into 'high' organic consumption.

We estimated relative risks as ORs by performing binary logistic regression with pre-eclampsia as the outcome and organic food consumption as the exposure.

We examined, as potential confounders, the following variables based on previous knowledge from the literature and our knowledge about characteristics associated with organic food consumption: maternal pre-pregnant BMI, maternal age, educational attainment, household income, gestational weight gain, cigarette smoking, alcohol consumption, exercise, total energy intake, overall food pattern and/or intake of main food groups and beverages (including sugar-sweetened beverages), intake of probiotic milk, and dietary supplement use. Covariates which were included in the final analysis were associated with both the exposure and the outcome $(\mathrm{p}<0.100)$ : maternal pre-pregnant BMI, maternal age, educational attainment, gestational weight gain, cigarette smoking, total energy intake and overall food pattern. In addition, known risk factors were included (hypertension prior to pregnancy and maternal height). Maternal height, total energy intake, and BMI were used as continuous variables in the model because the associations between these variables and the outcome were linear and the results were similar whether the variables were modelled as continuous or categorical. Maternal age was, however, modelled as categories due to a nonlinear association with organic food consumption.

To take into account that frequent consumers of organic food often report use of more than one of the six organic food groups, we additionally adjusted for 'any consumption' of organic food groups, defined by having a sum index above 6 , which corresponds to having reported eating organic food 'often' for at least one of the six food categories. This will, to some degree, overadjust the model, as consumption of organic vegetables is also included in the sum index. We tested for interaction between reported consumption of organic food and the confounders. Participants with missing data on potential confounding variables were categorised in a 'missing' category. In total, 1216 (4.3\%) had missing data on education and income, and excluding these in the adjusted models did not substantially change the results. Statistical analyses were performed using the statistical software PASW statistics V.17 (SPSS Inc, IBM Company, Chicago, Illinois, USA).

\section{RESULTS}

\section{Participant characteristics and organic food consumption}

Among the 28192 women in this study, the majority (14 566) reported that they never/rarely ate organic food, $11133(39.8 \%)$ had a combined scores reflecting use of at least one organic food 'sometimes', $1987(7 \%)$ had scores reflecting use of at least one organic food 'often' and 506 (1.8\%) had scores reflecting use of any organic food 'mostly'. Women who reported higher frequency of organic food differed from those who reported low consumption. The frequent organic users were younger, had lower BMI and reported higher energy intake than women with low organic consumption. There were also differences with regard to smoking and education, but the most significant difference was seen for higher adherence to a healthy food pattern (table 1).

Table 1 Maternal characteristics associated with consumption of organic food among 28192 pregnant women in the Norwegian Mother and Child Cohort Study 2002-2008

\begin{tabular}{|c|c|c|}
\hline \multirow[b]{2}{*}{ n (\%) } & \multicolumn{2}{|c|}{$\begin{array}{l}\text { Consumption of any } \\
\text { organic food group, } \\
\text { (sum index) }\end{array}$} \\
\hline & $\begin{array}{l}\text { Low } \\
25699(91.2)\end{array}$ & $\begin{array}{l}\text { Frequent } \\
2493(8.8)\end{array}$ \\
\hline & Mean $\pm S D$ & Mean \pm SD \\
\hline Maternal age, years & $28.6 \pm 4.3$ & $27.6 \pm 4.9^{\star \star}$ \\
\hline Maternal body mass index & $23.8 \pm 4.1$ & $23.3 \pm 3.9^{\star \star}$ \\
\hline Gestational weight gain, kg & $15.2 \pm 6.0$ & $15.5 \pm 6.5 \dagger$ \\
\hline \multirow[t]{2}{*}{ Energy intake, MJ/day } & $9.51 \pm 2.5$ & $10.0 \pm 2.9^{\star \star}$ \\
\hline & Per cent & Per cent \\
\hline Maternal education $\leq 12$ years & 25.5 & $37.7^{\star \star}$ \\
\hline Maternal education $17+$ years & 27.1 & $28.6^{\star}$ \\
\hline Smoking in pregnancy & 6.6 & $11.0^{\star \star}$ \\
\hline High household income§ & 29.7 & $23.1^{\star \star}$ \\
\hline Alcohol in pregnancy (yes/no) & 9.3 & 9.3 \\
\hline $\begin{array}{l}\text { Hypertension prior to } \\
\text { pregnancy (yes/no) }\end{array}$ & 0.5 & $0.2^{*}$ \\
\hline $\begin{array}{l}\text { High score 'healthy' } \\
\text { food patternๆ (yes/no) }\end{array}$ & 36.0 & $50.2^{\star *}$ \\
\hline \multicolumn{3}{|c|}{$\begin{array}{l}\text { Independent samples t test (continuous variables), } \chi^{2} \text { (categorical } \\
\text { variables): }{ }^{*} p<0.05,{ }^{* *} p<0.001,+0.05>p<0.01 . \\
\text { †Comprise occasional and daily smoking. } \\
\S \text { High income denotes that both participant and her partner have } \\
\text { annual income } \geq 300000 \text { NOK. } \\
\text { १High score denotes upper third on pattern scores. The food } \\
\text { pattern is described in detail in Torjusen } \text { et } a l^{33}\end{array}$} \\
\hline
\end{tabular}


Consumption of organic food and risk of pre-eclampsia

The number of participants diagnosed with preeclampsia was $1491(5.3 \%)$. We found no associations with pre-eclampsia for high intake of organic fruit, cereals, milk/dairy, eggs or milk, or the combined index reflecting total organic consumption. However, lower risk was indicated for high intake of organic vegetables (table 2). Adjusting for any consumption of the organic food groups (sum index low/frequent) strengthened the association between organic vegetables and preeclampsia, in spite of organic vegetables also being included in the 'any organic' variable (table 2). The association between consumption of organic vegetables and pre-eclampsia did not reach statistical significance when examined according to the four alternative answers, but a dose-response relationship was indicated ( $p$ trend 0.010; figure 2). However, when the 'often' and 'mostly' groups were combined into 'high' and the 'never/rarely' and 'sometimes' groups were combined into 'low' consumption of organic vegetables, the association with pre-eclampsia reached statistical significance (adjusted $\mathrm{OR}=0.75,95 \%$ CI 0.60 to 0.95 ; model 1 , table 3). Higher scores on the 'healthy' food pattern was also associated with lower risk of pre-eclampsia (OR tertile 2 vs tertile $10.80,95 \%$ CI 0.70 to 0.91 , and OR tertile 3 vs tertile 10.73 , $95 \%$ CI 0.64 to 0.84 ; model 1 , table 3 ). Because women who report use of organic food also have higher adherence to the 'healthy' diet, the 'healthy' food scores were included among the confounding variables (model 2, table 3). This resulted in wider CIs for both organic vegetables and the 'healthy' diet, but the associations remained statistically significant for organic vegetable consumption, with $\mathrm{OR}=0.79(95 \%$ CI 0.62 to 0.99 ), and for the food pattern, with OR tertile 3 vs tertile 10.74 (95\% CI 0.64 to 0.85$)$. Additional adjustment for any consumption of the organic food groups (sum index low/frequent) strengthened the association between organic vegetables and pre-eclampsia (data not shown). As previously reported, women who consumed organic vegetables had higher intakes of seafood, milk, iodine, calcium and several other foods and nutrients than those with no or low organic vegetable consumption. ${ }^{33}$

However, no food or nutrient intake attenuated the association of interest. Adjusting for single food groups, e.g. fish or milk, or for specific nutrients, e.g. iodine or calcium, did not change the association between consumption of organic vegetables and pre-eclampsia. This supports that adjusting for the overall dietary pattern accounts for the observed differences in food and nutrient intakes between women with high and low intake of organic vegetables.

No interactions were observed between use of organic vegetables and the food pattern, maternal age, education, BMI or smoking. Rerunning the association between organic vegetable consumption and pre-

Table 2 Associations between consumption of organic food groups and risk of pre-eclampsia among 28192 pregnant women in the Norwegian Mother and Child Cohort Study 2002-2008

\begin{tabular}{|c|c|c|c|c|}
\hline $\begin{array}{l}\text { Organic food } \\
\text { group }\end{array}$ & Total $\mathbf{n}$ & $\begin{array}{l}\text { Pre-eclampsia } \\
\text { n (\%) }\end{array}$ & $\begin{array}{l}\text { Unadjusted } \\
\text { OR (95\% Cl) }\end{array}$ & $\begin{array}{l}\text { Adjusted for consumption } \\
\text { of any organic food group, } \\
\text { (sum index low/frequent) } \\
\text { OR ( } 95 \% \mathrm{Cl} \text { ) }\end{array}$ \\
\hline & 28192 & $1491(5.3)$ & & \\
\hline \multicolumn{5}{|c|}{ Organic consumption in any food group (sum index) } \\
\hline Low & 25699 & $1368(5.3)$ & 1 & \\
\hline Frequent & 2493 & $123(4.9)$ & 0.92 (0.76 to 1.12$)$ & \\
\hline \multicolumn{5}{|l|}{ Vegetables } \\
\hline Low & 26241 & $1410(5.4)$ & 1 & 1 \\
\hline High & 1951 & $81(4.2)$ & 0.76 (0.61 to 0.96$)$ & 0.68 (0.50 to 0.92$)$ \\
\hline \multicolumn{5}{|l|}{ Fruit } \\
\hline Low & 26416 & $1404(5.3)$ & 1 & 1 \\
\hline High & 1776 & $87(4.9)$ & $0.92(0.73$ to 1.15$)$ & 0.96 (0.70 to 1.32$)$ \\
\hline \multicolumn{5}{|l|}{ Cereals } \\
\hline Low & 26403 & $1395(5.3)$ & 1 & 1 \\
\hline High & 1789 & $96(5.4)$ & $1.02(0.82$ to 1.26$)$ & $1.18(0.87$ to 1.61$)$ \\
\hline \multicolumn{5}{|l|}{ Milk/dairy } \\
\hline Low & 26155 & $1383(5.3)$ & 1 & 1 \\
\hline High & 2037 & $109(5.4)$ & $1.03(0.83$ to 1.24$)$ & $1.14(0.87$ to 1.50$)$ \\
\hline \multicolumn{5}{|l|}{ Eggs } \\
\hline Low & 25602 & $1363(5.3)$ & 1 & 1 \\
\hline High & 2590 & $128(4.9)$ & $0.93(0.77$ to 1.11$)$ & 0.95 (0.76 to 1.18$)$ \\
\hline \multicolumn{5}{|l|}{ Meat } \\
\hline Low & 27037 & 1425 & 1 & 1 \\
\hline High & 1155 & $66(5.7)$ & $1.09(0.84$ to 1.40$)$ & $1.28(0.92$ to 1.79$)$ \\
\hline
\end{tabular}


Table 3 Associations between consumption of organic vegetables and risk of pre-eclampsia among 28192 pregnant women in the Norwegian Mother and Child Cohort Study 2002-2008

\begin{tabular}{|c|c|c|c|c|c|c|c|}
\hline & Total $\mathbf{n}$ & $\begin{array}{l}\text { Pre-eclampsia } \\
\mathrm{N}(\%)\end{array}$ & $\begin{array}{l}\text { Crude model } \\
\text { OR }(95 \% \mathrm{Cl})\end{array}$ & $\begin{array}{l}\text { Adjusted model } 1^{*} \\
\text { OR }(95 \% \mathrm{Cl})\end{array}$ & p Value & $\begin{array}{l}\text { Adjusted model } 2 \dagger \\
\text { OR }(95 \% \mathrm{Cl})\end{array}$ & p Value \\
\hline & 28192 & $1491(5.3)$ & & & & & \\
\hline \multicolumn{8}{|c|}{ Organic vegetables } \\
\hline Low & 26241 & $1410(5.4)$ & 1 & 1 & & 1 & \\
\hline High & 1951 & $81(4.2)$ & 0.76 (0.61 to 0.96$)$ & 0.75 (0.60 to 0.95$)$ & 0.017 & $0.79(0.62$ to 0.99$)$ & 0.043 \\
\hline \multicolumn{8}{|c|}{ Scores on a 'healthy' food pattern $\ddagger$} \\
\hline Tertile 1 & 8369 & $556(6.6)$ & 1 & 1 & & 1 & \\
\hline Tertile 2 & 9320 & $480(5.2)$ & 0.76 (0.67 to 0.87$)$ & $0.80(0.70$ to 0.91$)$ & & 0.81 (0.71 to 0.92$)$ & 0.001 \\
\hline Tertile 3 & 10503 & 455 (4.3) & 0.64 (0.56 to 0.72$)$ & $0.73(0.64$ to 0.84$)$ & 0.001 & 0.74 (0.64 to 0.85$)$ & $<0.001$ \\
\hline $\mathrm{p}$ Trend & & & $<0.001$ & $<0.001$ & $<0.001$ & $<0.001$ & \\
\hline
\end{tabular}

*Model adjusted for hypertension prior to pregnancy, pre-pregnant body mass index, maternal height, maternal age, maternal education, household income, maternal smoking in pregnancy, total energy intake and gestational weight gain.

†Model adjusted for all of the above and mutual adjustment for organic vegetable consumption and 'healthy' food scores.

†Food pattern described in detail in Torjusen et al. ${ }^{33}$

eclampsia separately in each stratum (tertiles) of food pattern scores resulted in risk estimates of $0.87,0.77$ and 0.79 for tertiles 1,2 and 3. Likewise, when stratifying women by BMI $\geq 25$ and $<25$ the risk estimates were 0.76 and 0.82 , respectively.

When dividing pre-eclampsia in subgroups by time of onset or severity, the risk estimates were lower than 1 for all, but borderline significantly lower risk was indicated for use of organic vegetables only for the subtypes late-onset pre-eclampsia and mild pre-eclampsia, which were the subgroups with the highest number of cases (table 4).

\section{DISCUSSION}

The main finding of this study was that women who reported eating organically grown vegetables 'often' or 'mostly' had lower risk of developing pre-eclampsia than women who reported not consuming organic vegetables or to do so less frequently. This association was observed

Table 4 Associations between consumption of organic vegetables and subgroups of pre-eclampsia among 28192 pregnant women in the Norwegian Mother and Child Cohort Study 2002-2008

\begin{tabular}{|c|c|c|c|c|c|c|c|}
\hline & $\mathbf{N}$ & Per cent & $\begin{array}{l}\text { High } \\
\text { consumption, } \\
\text { organic } \\
\text { vegetables (\%) }\end{array}$ & $\begin{array}{l}\text { Adjusted model* } \\
\text { OR }(95 \% \mathrm{Cl})\end{array}$ & p Value & $\begin{array}{l}\text { Adjusted model† } \\
\text { OR }(95 \% \mathrm{Cl})\end{array}$ & p Value \\
\hline \multicolumn{8}{|c|}{ Subtypes by time of onset } \\
\hline \multicolumn{8}{|c|}{ Early-onset pre-eclampsiał } \\
\hline Yes & 142 & 0.5 & 0.4 & $0.69(0.32$ to 1.48$)$ & 0.34 & $0.75(0.35$ to 1.62$)$ & 0.46 \\
\hline No & 26701 & 94.7 & 95.8 & & & & \\
\hline \multicolumn{8}{|c|}{ Late-onset pre-eclampsia } \\
\hline Yes & 1349 & 4.8 & 3.8 & $0.76(0.60$ to 0.97$)$ & 0.030 & $0.79(0.62$ to 1.01$)$ & 0.063 \\
\hline No & 26701 & 94.7 & 95.8 & & & & \\
\hline \multicolumn{8}{|c|}{ Subtypes by clinical severity } \\
\hline \multicolumn{8}{|c|}{ Mild pre-eclampsia } \\
\hline Yes & 841 & 3.0 & 2.2 & $0.70(0.51$ to 0.96$)$ & 0.029 & $0.73(0.53$ to 1.00$)$ & 0.051 \\
\hline No & 26701 & 94.7 & 95.8 & & & & \\
\hline \multicolumn{8}{|c|}{ Severe pre-eclampsia§ } \\
\hline Yes & 434 & 1.5 & 1.4 & $0.91(0.61$ to 1.34$)$ & 0.62 & $0.97(0.65$ to 1.43$)$ & 0.86 \\
\hline No & 26701 & 94.7 & 95.8 & & & & \\
\hline \multicolumn{8}{|c|}{ Unspecified pre-eclampsia } \\
\hline Yes & 216 & 0.8 & 0.5 & $0.66(0.35$ to 1.24$)$ & 0.20 & $0.67(0.35$ to 1.27$)$ & 0.22 \\
\hline No & 26701 & 94.7 & 95.8 & & & & \\
\hline
\end{tabular}


independently of a healthy food pattern including a generally higher vegetable intake.

\section{Strengths}

The major strengths of this study are the large sample of women from all regions of Norway, the prospective design and the detailed information on a wide range of potential confounding factors. All age and socioeconomic groups are represented in the study group. Validated pre-eclampsia diagnosis was obtained from the Medical Birth Registry of Norway. ${ }^{37}$ Women were unaware of the outcome of pregnancy when dietary data and information about consumption of organic food was collected, which reduces the likelihood of misreporting as a consequence of the disease.

The food frequency questionnaire used in our study has been extensively validated and shown to be a valuable tool for ranking pregnant women according to high and low intakes of energy, nutrients and foods. ${ }^{36} 38-40$ The smoking variable, as used in the present study (non-smokers, occasional smokers and daily smokers), has been validated against plasma cotinine in a sub-sample of 2997 women in the Norwegian Mother and Child Cohort Study. ${ }^{41}$ A study of potential self-selection bias in the Norwegian Mother and Child Cohort Study found no significant differences between the eight evaluated exposure-outcome associations in the cohort and the total pregnant population in Norway during the same period, ${ }^{42}$ nor does it appear to compromise validity of exposure-outcome associations related to autism in a substudy of the Norwegian Mother and Child Cohort Study. ${ }^{43}$ Our findings are likely to be generalisable outside of Norway, because although consumption of organic food is embedded in specific structural and cultural features of the food system in any particular country, there are similarities in characteristics and motivations among consumers of organic food across Europe. ${ }^{31}$

\section{Limitations}

The exposure variable is based on 6 questions about specified organic food groups, with four alternative frequency categories given as the answer options. These frequency categories may have been interpreted differently among participants as the distinction between 'sometimes' and 'often' or between 'often' and 'mostly' might not be clear. A potential misclassification resulting from this should however be equally distributed among women who did and did not develop pre-eclampsia. Furthermore, imprecision in the exposure variable is likely to cause attenuation in the risk estimation, in this case attenuation towards the null of the estimated associations between organic food practices and pre-eclampsia. $^{44}$

Although the food frequency questionnaire of the Norwegian Mother and Child Cohort Study has been validated, the question about use of organic food was not evaluated. It would have strengthened the study if we had had access to biological material and could have assessed pesticide and secondary plant metabolite levels in the participants' urine.

In spite of a large study population, the number of frequent organic vegetable consumers (1951) was relatively low $(6.9 \%)$, which was a limitation in the analysis of preeclampsia subgroups, e.g. late vs early onset. The risk estimates in subgroup analyses were indicative of lower risk, but the low numbers resulted in wide CIs. A further limitation of this study is that the data available do not allow the assessment of impact of pre-pregnancy nutritional status, which may be a confounder of the relationship shown.

Since the study is observational, no causal implications can be drawn, and although confounding by other variables was carefully considered, residual confounding cannot be excluded.

\section{Possible explanations for findings}

We will, in the following, outline some properties of organic vegetables that could possibly contribute to explain our findings of a reduced risk of pre-eclampsia, emphasising that these are purely hypothetical suggestions since we only have associations from epidemiological data. Our suggestions of possible explanations are based on the following characteristics of a diet including organically produced vegetables rather than conventional vegetables: (1) lower dietary pesticide exposure; (2) higher intake of secondary plant metabolites and (3) possibly a different microflora on organic vegetables, which could affect human (maternal) intestinal microbiota in a beneficial way. Furthermore, pesticides, or the absence of them, might impact the composition of the gut microbiota.

\section{Lower pesticide exposure}

Although the most persistent pesticides have been banned in most countries, they may still be present at trace levels in foods due to their long environmental and biological half-lives. It is well established that a diet consisting of predominantly organically produced foods significantly reduces the exposure to organophosphorous pesticides. ${ }^{26}{ }^{45}$ Chlorpyrifos (CPF) has been shown to increase permeability of the intestine in an in vitro model based on an enterocyte cell line. ${ }^{46}$ Increased permeability of the intestine ('leaky gut') may induce inflammation. ${ }^{47}$

Some recent studies have reported an association between pesticide exposure or residues in the body and obesity and type 2 diabetes. ${ }^{48-50}$ In a prospective study, exposure to organochlorine pesticides was shown to increase the risk of obesity, dyslipidaemia and insulin resistance among participants without diabetes. ${ }^{49}$ Organochlorine pesticides, particularly chlordane, predicted incidents of type 2 diabetes in a nested casecontrol study. ${ }^{51}$ Chemicals, such as organochlorine pesticides, may cause obesity by altering homoeostatic metabolic set points, disrupting appetite controls, perturbing 
lipid homoeostasis to promote adipocyte hypertrophy or stimulating adipogenic pathways that enhance adipocyte hyperplasia during development or in adults. ${ }^{47} 5253$ Since obesity and dyslipidaemia (hypertriglyceridaemia) are also associated with the development of preeclampsia, ${ }^{54}$ lower exposure of pesticide residues may provide a possible explanation of lower risk of preeclampsia with the inclusion of organically produced vegetables in the diet.

Furthermore, a diet with lower levels of pesticide residues may reduce proneness to inflammations by affecting the composition of the gut microbiota in a beneficial way. In a model of the human intestinal microbial ecosystem, as well as in rat studies, it has been shown that chronic exposure of CPF selectively altered the intestinal microflora. ${ }^{55}$ Proliferation of the total intestinal flora was observed, mainly due to an increase in certain subpopulations such as the Enterococcus spp and Bacteroides spp, while there was a decrease in the numbers of beneficial bacteria such as bifidobacteria and lactobacilli. ${ }^{55}$

\section{Higher intake of secondary plant metabolites}

A majority of studies comparing the contents of secondary plant metabolites in organically vs conventionally grown fruits and vegetables report higher contents of these compounds in organic products. ${ }^{28} 5657$ Brandt et $a l^{28}$ reported substantially higher contents of defence-related secondary metabolites, represented by phenolic acids; other defence compounds (tannins, alkaloids, chalcones, stilbenes, flavanones and flavanols, hop acids, coumarins and aurones), and total phenolics. The authors estimate, based on a meta-analysis of 65 papers, that if a person changes from consuming exclusively conventional fruit and vegetables to consuming the organic alternatives of the same products in the same amounts, the intake of all secondary metabolites would increase by approximately $12 \%$, and the intake of more specifically defence-related secondary metabolites would increase by approximately $16 \% .^{28}$ Whether such a difference has health-related implications remains to be shown. Baxter et a $\tilde{l}^{7}$ showed that soups based on organically grown plants had higher content of salicylic acid than those made from non-organic plants.

In terms of human health, many of these compounds, such as salicylic acid and polyphenols, have antiinflammatory properties. ${ }^{58}$ Furthermore, polyphenols are a class of dietary substances that act as a 'prebiotic', influencing the intestinal microflora in a beneficial way. ${ }^{59}$

In our study, adjusting for single foods or nutrients did not attenuate the association between consumption of organic vegetables and pre-eclampsia. Furthermore, the association between consumption of organic vegetables and pre-eclampsia was independent of the reduced risk also indicated by an overall healthy diet, supporting the hypothesis that organic vegetables may provide higher amount or different composition of non- nutrients. By providing higher dietary intakes of secondary plant metabolites, organically grown vegetables may contribute to a less inflammation-prone milieu in the maternal gut, as well as an improved antioxidant status, thereby possibly reducing the risk of pre-eclampsia.

\section{Different microflora on organically grown vegetables compared with conventionally grown}

The gut is a major immune organ, and the gut microbiota shapes intestinal immune response during health and disease. ${ }^{59-61}$ It has been shown that the human gut microbiome can rapidly respond to altered diet, ${ }^{62}$ and it is becoming increasingly clear that the effect of the microbial ecology of the gut goes beyond the local gut immune system and is implicated in immune-related disorders, such as type 2 diabetes and obesity. ${ }^{63-65}$

It has been reported that children growing up in families with an anthroposophical lifestyle, including consumption of organic/biodynamic food and fermented vegetables, have lower risk of developing atopic diseases, and this is associated with development of a more beneficial intestinal microflora compared with children not living in families with anthroposophical lifestyles. ${ }^{66-68}$ It is, however, unclear whether these observed effects are related to the consumption of organic food as such, or the additional consumption of fermented vegetables. It may be hypothesised that organic farming practices not only enhance a richer, more diverse microflora in the soil but also on fresh produce such as vegetables and that this in turn may influence the dietary intake of probiotic substances. ${ }^{29} 6970$ A possible explanation why the results in this study showed an association between organic vegetables but not with organic fruits and preeclampsia might be that people are more likely to peel fruit, resulting in lower exposure to microbes than for raw vegetables.

The relevance of the integrity of the intestinal microflora for the development of pre-eclampsia is supported by the evidence from studies finding protective effects of probiotics, ${ }^{14}{ }^{71}$ and evidence supporting the hypothesis that plant foods may influence pre-eclampsia through intestinal anti-inflammatory mechanisms. ${ }^{72}$ Brantsæter and colleagues found that probiotic milk (containing Lactobacillus bacteria) is associated with reduced risk of pre-eclampsia, and it is hypothesised that the Lactobacillus probiotics in this study may have suppressed the Gram-negative bacterial lipopolysaccharide (LPS) expression to reduce inflammation. ${ }^{14}$ This mechanism would be in agreement with other studies which found that lactobacilli influenced the LPS response to reduce overall systemic inflammation levels. ${ }^{73}$

\section{Comparison with other studies}

To the best of our knowledge, this is the first study investigating a potential association between consumption of organically grown food during pregnancy and lower risk of pre-eclampsia. To date, only a limited number of studies have examined possible human health outcomes 
associated with consumption of organic foods. A casecontrol study from Denmark examined maternal use of organic food and hypospadias in male neonates. They found a higher likelihood of hypospadias in the offspring among women who never used organic high fat dairy foods compared with those who often used organic high fat dairy products. ${ }^{74}$ Reduced risk of allergic (IgE) sensitisation in infancy, lower prevalences of atopic diseases, differences in the intestinal microflora and lower levels of salivatory cortisol have been shown in children living in families with an anthroposophic lifestyle, in which consumption of organic/biodynamic food is one of several characteristics. ${ }^{66} \quad 67 \quad 75-78$ Kummeling et $a l^{67}$ found that children who consumed dairy products of which more than $90 \%$ were organically produced had a lower risk of eczema at age 2 than children who consumed dairy products of which less than $50 \%$ were organically produced.

\section{CONCLUSIONS AND POLICY IMPLICATIONS}

Large knowledge gaps remain in our understanding of how the consumption of organic foods and related lifestyle practices influence the health of mother and child. It is important that questions about organic food choices are incorporated into large new and ongoing studies. The present study suggests a lower risk of preeclampsia in pregnant Norwegian women who reported frequent consumption of organically produced vegetables compared with those with no or low consumption of such foods. Increased consumption of plant food, including vegetables, is recommended to all pregnant women, and this study shows that choosing organically grown vegetables may yield additional benefits. Future studies need to confirm the observed association and if so further address possible causal relationships.

\author{
Author affiliations \\ ${ }^{1}$ National Institute for Consumer Research (SIFO), Oslo, Norway \\ ${ }^{2}$ Division of Environmental Medicine, Norwegian Institute of Public Health, \\ Oslo, Norway \\ ${ }^{3}$ Office of the Director-General, Norwegian Institute of Public Health, Oslo, \\ Norway \\ ${ }^{4}$ Division of Epidemiology, The Norwegian Institute of Public Health, Oslo, \\ Norway \\ ${ }^{5}$ Department of Plant Sciences, Norwegian University of Life Sciences, Ås, \\ Norway \\ ${ }^{6}$ Nofima, Ås, Norway \\ ${ }^{7}$ Department of Food Science, University of Copenhagen, Copenhagen, \\ Denmark \\ ${ }^{8}$ Uppsala University Hospital, Uppsala, Sweden \\ ${ }^{9}$ Vidarkliniken, Järna, Sweden \\ ${ }^{10}$ Department of General Practice and Community Medicine, Faculty of \\ Medicine, University of Oslo, Norway
}

Acknowledgements The authors are grateful to all the families in Norway participating in this ongoing cohort study.

Contributors $\mathrm{HT}, \mathrm{ALB}, \mathrm{HMM}$ and $\mathrm{MH}$ conceived the study, and all authors contributed to the study design. HT, HMM and JA obtained funding for the study. HT, ALB, MH, HS, GL, TN and HMM prepared the data. HT conducted the statistical analysis, drafted the manuscript and had the primary responsibility for the final content. JA, LSB, HS, GL, TN, JS, GH-0 and GR contributed to the interpretation of the results. All authors critically reviewed, read and approved the final version of the manuscript. HT is the guarantor.

Funding The present study was supported by a grant from The Research Council of Norway, The Food Programme (project no. 176827). The Norwegian Mother and Child Cohort Study is supported by the Norwegian Ministry of Health and the Ministry of Education and Research, NIH/NIEHS (contract no N01-ES-75558), NIH/NINDS (grant no. 1 U01 NS 047537-01 and grant no. 2 U01 NS 047537-06A1). All authors are independent from funders.

\section{Competing interests None.}

Patient consent Obtained.

Ethics approval The Norwegian Mother and Child Cohort Study was approved by the Regional Committee for Ethics in Medical Research (REK nr S-97045 /S-95113) and the Data Inspectorate in Norway.

Provenance and peer review Not commissioned; externally peer reviewed.

Data sharing statement No additional data are available.

Open Access This is an Open Access article distributed in accordance with the Creative Commons Attribution Non Commercial (CC BY-NC 4.0) license, which permits others to distribute, remix, adapt, build upon this work noncommercially, and license their derivative works on different terms, provided the original work is properly cited and the use is non-commercial. See: http:// creativecommons.org/licenses/by-nc/4.0/

\section{REFERENCES}

1. Sibai B, Dekker G, Kupferminc M. Pre-eclampsia. Lancet 2005;365:785-99.

2. Duley L, Meher S, Abalos E. Management of pre-eclampsia. BMJ 2006;332:463-8.

3. Dusse LM, Rios DR, Pinheiro MB, et al. Pre-eclampsia: relationship between coagulation, fibrinolysis and inflammation. Clin Chim Acta 2011;412:17-21.

4. James JL, Whitley GS, Cartwright JE. Pre-eclampsia: fitting together the placental, immune and cardiovascular pieces. J Pathol 2010;221:363-78

5. Saito S, Shiozaki A, Nakashima A, et al. The role of the immune system in preeclampsia. Mol Aspects Med 2007;28:192-209.

6. Szarka A, Rigo J Jr, Lazar L, et al. Circulating cytokines, chemokines and adhesion molecules in normal pregnancy and preeclampsia determined by multiplex suspension array. BMC Immunol 2010;11:59.

7. Hernandez-Diaz S, Toh S, Cnattingius S. Risk of pre-eclampsia in first and subsequent pregnancies: prospective cohort study. BMJ 2009;338:b2255.

8. Dekker GA, Sibai BM. Etiology and pathogenesis of preeclampsia: current concepts. Am J Obstet Gynecol 1998;179:1359-75.

9. Magnussen EB, Vatten LJ, Lund-Nilsen TI, et al. Prepregnancy cardiovascular risk factors as predictors of pre-eclampsia: population based cohort study. BMJ 2007;335:978.

10. Roberts JM, Balk JL, Bodnar LM, et al. Nutrient involvement in preeclampsia. J Nutr 2003;133(5 Suppl 2):1684S-92S.

11. $\mathrm{Xu} \mathrm{H}$, Shatenstein $\mathrm{B}$, Luo ZC, et al. Role of nutrition in the risk of preeclampsia. Nutr Rev 2009;67:639-57.

12. Brantsaeter AL, Haugen M, Samuelsen SO, et al. A dietary pattern characterized by high intake of vegetables, fruits, and vegetable oils is associated with reduced risk of preeclampsia in nulliparous pregnant Norwegian women. J Nutr 2009;139:1162-8.

13. Borgen I, Aamodt G, Harsem N, et al. Maternal sugar consumption and risk of preeclampsia in nulliparous Norwegian women. Eur $J$ Clin Nutr 2012;66:920-5.

14. Brantsaeter AL, Myhre R, Haugen M, et al. Intake of probiotic food and risk of preeclampsia in primiparous women: the Norwegian Mother and Child Cohort Study. Am J Epidemiol 2011;174:807-15.

15. Haugen M, Brantsaeter AL, Trogstad L, et al. Vitamin D supplementation and reduced risk of preeclampsia in nulliparous women. Epidemiology 2009;20:720-6.

16. Qiu C, Coughlin KB, Frederick IO, et al. Dietary fiber intake in early pregnancy and risk of subsequent preeclampsia. Am J Hypertens 2008;21:903-9.

17. Patrelli TS, Dall'asta A, Gizzo S, et al. Calcium supplementation and prevention of preeclampsia: a meta-analysis. J Matern Fetal Neonatal Med 2012;25:2570-4. 
18. Hofmeyr G, Belizan J, von DP. Low-dose calcium supplementation for preventing pre-eclampsia: a systematic review and commentary. BJOG 2014;121:951-7.

19. Salles AM, Galvao TF, Silva MT, et al. Antioxidants for preventing preeclampsia: a systematic review. Sci World J 2012;2012:243476.

20. IFOAM. 2014. http://www.ifoam.org/en/organic-landmarks/ principles-organic-agriculture

21. Debio. 2014. http://www.debio.no/forsiden/information-in-english

22. Smith-Spangler C, Brandeau ML, Olkin I, et al. Are organic foods safer or healthier? Ann Intern Med 2013;158:297-300.

23. Crinnion WJ. Organic foods contain higher levels of certain nutrients, lower levels of pesticides, and may provide health benefits for the consumer. Altern Med Rev 2010;15:4-12.

24. Guéguen L, Pascal D. Le point sur la valeur nutritionnelle et sanitaire des aliments issus de l'agriculture biologique. Cahiers de Nutrition et de Diététique 2010;45:130-43.

25. Baker BP, Benbrook CM, Groth E, et al. Pesticide residues in conventional, integrated pest management (IPM)-grown and organic foods: insights from three US data sets. Food Addit Contam 2002:19:427-46.

26. Curl CL, Fenske RA, Elgethun K. Organophosphorus pesticide exposure of urban and suburban preschool children with organic and conventional diets. Environ Health Perspect 2003;111:377-82.

27. Lu C, Barr DB, Pearson M, et al. A longitudinal approach to assessing urban and suburban children's exposure to pyrethroid pesticides. Environ Health Perspect 2006;114:1419-23.

28. Brandt K, Leifert C, Sanderson R, et al. Agroecosystem management and nutritional quality of plant foods: the case of organic fruits and vegetables. Crit Rev Plant Sci 2011;30:177-97.

29. Leff JW, Fierer N. Bacterial communities associated with the surfaces of fresh fruits and vegetables. PLOS ONE 2013;8:e59310.

30. Norwegian Agricultural Authority. Produksjon og omsetning av økologiske landbruksvarer. Rapport for 2013. (In Norwegian). 8/ 2014. 2014. Oslo, Norway.

31. Torjusen H, Kjærnes U, Sangstad L, et al. European consumers conceptions of organic food: a review of available research. Professional report no. 4-2004 ed. Oslo: National Institute for Consumer Research (SIFO); 2004.

32. Torjusen $\mathrm{H}$, Brantsaeter $\mathrm{A}$, Haugen $\mathrm{M}$, et al. Characteristics associated with organic food consumption during pregnancy; data from a large cohort of pregnant women in Norway. BMC Public Health 2010;10:775.

33. Torjusen H, Lieblein G, Naes T, et al. Food patterns and dietary quality associated with organic food consumption during pregnancy; data from a large cohort of pregnant women in Norway. BMC Public Health 2012;12:612.

34. Magnus $\mathrm{P}$, Irgens LM, Haug K, et al. Cohort profile: the Norwegian Mother and Child Cohort Study (MoBa). Int $J$ Epidemiol 2006;35:1146-50.

35. Irgens LM. The Medical Birth Registry of Norway. Epidemiological research and surveillance throughout 30 years. Acta Obstet Gynecol Scand 2000;79:435-9.

36. Meltzer HM, Brantsaeter AL, Ydersbond TA, et al. Methodological challenges when monitoring the diet of pregnant women in a large study: experiences from the Norwegian Mother and Child Cohort Study (MoBa). Matern Child Nutr 2008;4:14-27.

37. Thomsen LC, Klungsoyr K, Roten LT, et al. Validity of the diagnosis of pre-eclampsia in the Medical Birth Registry of Norway. Acta Obstet Gynecol Scand 2013;92:943-50.

38. Brantsaeter AL, Haugen M, Julshamn $\mathrm{K}$, et al. Evaluation of urinary iodine excretion as a biomarker for intake of milk and dairy products in pregnant women in the Norwegian Mother and Child Cohort Study (MoBa). Eur J Clin Nutr 2009;63:347-54.

39. Brantsaeter AL, Haugen M, Rasmussen SE, et al. Urine flavonoids and plasma carotenoids in the validation of fruit, vegetable and tea intake during pregnancy in the Norwegian Mother and Child Cohort Study (MoBa). Public Health Nutr 2007;10:838-47.

40. Brantsaeter AL, Haugen M, Alexander J, et al. Validity of a new food frequency questionnaire for pregnant women in the Norwegian Mother and Child Cohort Study (MoBa). Matern Child Nutr 2008;4:28-43.

41. Kvalvik LG, Nilsen RM, Skjaerven R, et al. Self-reported smoking status and plasma cotinine concentrations among pregnant women in the Norwegian Mother and Child Cohort Study. Pediatr Res 2012;72:101-7.

42. Nilsen RM, Vollset SE, Gjessing HK, et al. Self-selection and bias in a large prospective pregnancy cohort in Norway. Paediatr Perinat Epidemiol 2009;23:597-608.

43. Nilsen RM, Suren P, Gunnes N, et al. Analysis of self-selection bias in a population-based cohort study of autism spectrum disorders. Paediatr Perinat Epidemiol 2013;27:553-63.
44. Parr CL, Veierod MB, Laake $\mathrm{P}$, et al. Test-retest reproducibility of a food frequency questionnaire (FFQ) and estimated effects on disease risk in the Norwegian Women and Cancer Study (NOWAC). Nutr J 2006;5:4

45. Lu C, Toepel K, Irish R, et al. Organic diets significantly lower children's dietary exposure to organophosphorus pesticides. Environ Health Perspect 2006;114:260-3.

46. Tirelli $\mathrm{V}$, Catone $\mathrm{T}$, Turco $\mathrm{L}$, et al. Effects of the pesticide clorpyrifos on an in vitro model of intestinal barrier. Toxicol In Vitro 2007;21:308-13.

47. Anders $\mathrm{HJ}$, Andersen $\mathrm{K}$, Stecher B. The intestinal microbiota, a leaky gut, and abnormal immunity in kidney disease. Kidney Int 2013;83:1010-16.

48. Dirinck E, Jorens PG, Covaci A, et al. Obesity and persistent organic pollutants: possible obesogenic effect of organochlorine pesticides and polychlorinated biphenyls. Obesity (Silver Spring) 2011;19:709-14.

49. Lee DH, Steffes MW, Sjodin A, et al. Low dose organochlorine pesticides and polychlorinated biphenyls predict obesity, dyslipidemia, and insulin resistance among people free of diabetes. PLOS ONE 2011;6:e15977.

50. Thayer KA, Heindel JJ, Bucher JR, et al. Role of environmental chemicals in diabetes and obesity: a National Toxicology Program workshop review. Environ Health Perspect 2012;120:779-89.

51. Lee DH, Steffes MW, Sjodin A, et al. Low dose of some persistent organic pollutants predicts type 2 diabetes: a nested case-control study. Environ Health Perspect 2010;118:1235-42.

52. Grun F, Blumberg B. Endocrine disrupters as obesogens. Mol Cell Endocrinol 2009;304:19-29.

53. Newbold RR, Padilla-Banks E, Jefferson WN. Environmental estrogens and obesity. Mol Cell Endocrinol 2009;304:84-9.

54. Niromanesh S, Shirazi M, Dastgerdy E, et al. Association of hypertriglyceridaemia with pre-eclampsia, preterm birth, gestational diabetes and uterine artery pulsatility index. Natl Med J India 2012;25:265-7.

55. Joly C, Gay-Queheillard J, Leke A, et al. Impact of chronic exposure to low doses of chlorpyrifos on the intestinal microbiota in the Simulator of the Human Intestinal Microbial Ecosystem (SHIME) and in the rat. Environ Sci Pollut Res Int 2013;20:2726-34.

56. Benbrook $\mathrm{C}$. The impacts of yield on nutritional quality: lessons from organic farming. Hort Sci 2009;44:12-14.

57. Baxter GJ, Graham AB, Lawrence JR, et al. Salicylic acid in soups prepared from organically and non-organically grown vegetables. Eur J Nutr 2001;40:289-92.

58. Rosa FT, Zulet MA, Marchini JS, et al. Bioactive compounds with effects on inflammation markers in humans. Int $J$ Food Sci Nutr 2012;63:749-65.

59. Bosscher D, Breynaert A, Pieters L, et al. Food-based strategies to modulate the composition of the intestinal microbiota and their associated health effects. J Physiol Pharmacol 2009;60(Suppl 6):5-11.

60. Maslowski KM, Mackay CR. Diet, gut microbiota and immune responses. Nat Immunol 2011;12:5-9.

61. Brandtzaeg P. Gate-keeper function of the intestinal epithelium Benef Microbes 2013;4:67-82.

62. David LA, Maurice CF, Carmody RN, et al. Diet rapidly and reproducibly alters the human gut microbiome. Nature 2014:505:559-63.

63. Cerf-Bensussan N, Gaboriau-Routhiau V. The immune system and the gut microbiota: friends or foes? Nat Rev Immunol 2010;10:735-44.

64. Panwar H, Rashmi HM, Batish VK, et al. Probiotics as potential biotherapeutics in the management of type 2 diabetes-prospects and perspectives. Diabetes Metab Res Rev 2013;29:103-12.

65. Jeffery IB, O'Toole PW. Diet-microbiota interactions and their implications for healthy living. Nutrients 2013;5:234-52.

66. Alm JS, Swartz J, Lilja G, et al. Atopy in children of families with an anthroposophic lifestyle. Lancet 1999;353:1485-8.

67. Kummeling I, Thijs $\mathrm{C}$, Huber M, et al. Consumption of organic foods and risk of atopic disease during the first 2 years of life in the Netherlands. Br J Nutr 2008;99:598-605.

68. Penders J, Thijs C, van den Brandt PA, et al. Gut microbiota composition and development of atopic manifestations in infancy: the KOALA Birth Cohort Study. Gut 2007;56:661-7.

69. Ottesen AR, White JR, Skaltsas DN, et al. Impact of organic and conventional management on the phyllosphere microbial ecology of an apple crop. J Food Prot 2009;72:2321-5.

70. Vitali B, Minervini G, Rizzello CG, et al. Novel probiotic candidates for humans isolated from raw fruits and vegetables. Food Microbiol 2012;31:116-25.

71. Lindsay KL, Walsh CA, Brennan L, et al. Probiotics in pregnancy and maternal outcomes: a systematic review. J Matern Fetal Neonatal Med 2013;26:772-8. 
72. North CJ, Venter CS, Jerling JC. The effects of dietary fibre on C-reactive protein, an inflammation marker predicting cardiovascular disease. Eur J Clin Nutr 2009;63:921-33.

73. Yeganegi M, Watson CS, Martins A, et al. Effect of Lactobacillus rhamnosus GR-1 supernatant and fetal sex on lipopolysaccharide-induced cytokine and prostaglandin-regulating enzymes in human placental trophoblast cells: implications for treatment of bacterial vaginosis and prevention of preterm labor. $A m$ J Obstet Gynecol 2009;200:532-8.

74. Christensen JS, Asklund C, Skakkebaek NE, et al. Association between organic dietary choice during pregnancy and hypospadias in offspring: a study of mothers of 306 boys operated on for hypospadias. J Urol 2013;189:1077-82.
75. Alfven T, Braun-Fahrlander C, Brunekreef B, et al. Allergic diseases and atopic sensitization in children related to farming and anthroposophic lifestyle-the PARSIFAL study. Allergy 2006:61:414-21.

76. Alm JS, Swartz J, Bjorksten B, et al. An anthroposophic lifestyle and intestinal microflora in infancy. Pediatr Allergy Immunol 2002;13:402-11.

77. Stenius F, Swartz J, Lindblad F, et al. Low salivary cortisol levels in infants of families with an anthroposophic lifestyle. Psychoneuroendocrinology 2010;35:1431-7.

78. Swartz J, Stenius F, Alm J, et al. Lifestyle and salivary cortisol at the age of 12 and 24 months. Acta Paediatr 2012; 101:979-84. 